\title{
Low Harmonics Single Phase Multilevel Power Inverter
}

\begin{abstract}
This study deals with the simulation and development of a single phase multilevel inverter. The aim of the study is to investigate the performance and features of transformer and transformer-less multilevel inverters. In order to generate sinusoidal wave with minimum THD, harmonic elimination method has been used to calculate conducting angle of each $\mathrm{H}-$ bridge. This generates the output waveform with certain voltage and low THD. PIC microcontroller has been used to generate the signals required to operate the system. The proposed circuit was simulated using Pspice/Orcad and the results were compared with the hardware experimental results and a good agreement has been found between simulation and laboratory results.
\end{abstract}

Keyword: Multilevel inverter; Harmonic elimination; Cascaded inverter. 